\title{
LEBANESE SOIL AND TERRAIN UNITES DELINEATION BASED ON DIGITAL ELEVATION MODELS
}

\author{
Doumit Jean A. * \\ *Lebanese university, department of geography \\ Beirut,Lebanon, jeandoumit@gmail.com
}

\begin{abstract}
The Soil and Terrain digital database (SOTER) stores attribute data on landform and soils, the United Nations Environmental Program (UNEP) create a soil and terrain digital database with a global coverage at a spatial resolution of one kilometer approximately.

For a little country as Lebanon such data with a very low resolution cannot be useful, Until recently, only manual methods were used to delineate SOTER (SOil and TERrain Digital Database) Units [21]. Theaimofourstudyisto apply aquantitativemethodtoderive terrain classes that match the physiography SOTER of the Lebanese territory at regional scale. According to SRTMdigital elevation model todefinetheSOTERTerrainUnit: hypsometry, slope, reliefintensity and stream density. Several GIS techniques were employed to translate the SOTER mapping concept. The four features are combined and vectorized to achieve the delineation of the SOTER Terrain unit's map at a spatial precision of 90 meters.
\end{abstract}

Keywords: Lebanon, soil, United Nations Environmental Program, GIS, mapping.

Introduction. Many national organizations collect soil and terrain data. This is done at various scales and using different mapping approaches, in accord with user requirements.

The Soil and Terrain digital database (SOTER) stores attribute data on landform and soils that are easily accessible. Initially, the idea of the SOTER begin in the mid-eighties by FAO, with the ISRIC-World Soil Information and the United Nations Environmental Program (UNEP), to create a soil and terrain digital database [3,15,31] with a global coverage of SOTER attribute data at a scale of 1:1 million approximately one kilometer of spatial resolution.

As a result of an agreement between ISRIC and Latin American countries in 1994 was the regional SOTER database for Latin America and the Caribbean (SOTERLAC) at a scale of 1:5 million [19, 30]. Then SOTER databases for Central and Eastern Europe (SOVEUR) [2, 16], Southern Africa (SOTERSAF), [17] and for Central Africa (SOTERCAF) $[14,27]$ have been completed at scales 1:2 million. National SOTER databases for individual countries, like Senegal, Tunisia, Argentina, Kenya, Nepal, China and Jordan at scale 1:1 million were compiled in a FAO coordinated program of Land Degradation Assessment in Dry lands [8, 14, 29].

National scale SOTER database for Lebanon till now is not made, for this reason our study came to solve the physiography (landform) side not the lithological one which means the shape delineation of the Lebanese SOTER and mapping its structure.

The Physisography (landform) is characterized by 4 differentiating features: hypsometry, slope, relief intensity and stream density. A GIS method based on the four differentiating features was applied for the delineation and extraction of the SOTER physisography units from Shuttle Radar Topography Mission (SRTM) digital elevation models to form a second derivative SOTER physiography map.

ISRIC and its partners (IUSS, FAO, UNEP and national soil survey organizations) developed a uniform methodology and software tools to compile standardized, harmonized 'area-class' maps and associated databases using available data sources.

These area-class products present derived property estimates for over 15 soil properties (e.g., $\mathrm{pH}$, texture, caption exchange capacity, organic carbon and nitrogen, bulk density, and water holding capacity) for standardized depths. These products are widely applied in a range of environmental and agricultural studies.

The target of our study is to delineate these 'area-class' of the Lebanese territory using a series of GIS algorithms applied for the first time on this area.

As a first step the methodology uses a stepwise approach for identifying geomorphological terrain features landforms: hypsometry, slope, relief intensity and stream density.

Classification and combination of these feature comes in a second last step in delineation of SOTER terrain units.

Lebanon is a mountainous land with an elevation interval 0-3080 above the sea level laying on an area of 10452 square kilometer, its physiography ranges from coastal plains in low lands, to very rugged and snow covered high mountains. In such landscapes, topography is an overruling soil forming factor and responsible for a large variability in soil characteristics, distribution and soil depth.

\section{Material and methods.}

Source materials. This work of a detailed terrain database relied largely on the land system map at national level, this land system map gives a detailed description of landform at a spatial resolution of 90 meters of original Digital Elevation Model (DEM) based on Shuttle radar topography mission (SRTM), It produced digital topographic data on 3 arcsecond grid which roughly translates to a 90-meter horizontal spatial resolution and an absolute horizontal and vertical accuracies are given as equal to 20 meters (circular error at $90 \%$ confidence) and 16 meters (linear error at $90 \%$ confidence).

The SRTM data of the study area is given in geographic coordinates (using as horizontal datum the WGS84 ellipsoid). The SRTM grid values are provided in terms of orthometric heights with respect to the geoid model computed from the EGM96 geopotential model. 
Since SRTM data became widely available and free of charges, many studies utilized them for applications in topography [13], geomorphology [23, 41, 37], vegetation cover studies [32], and urban studies [20].

Hypsometry. The possibility of using DEM with hypsometric analysis can reveal the characters of elevation ranges, the evolution of these elevation ranges of different orders may be a consequence of the different factors of relief formation and the presence of genetically heterogeneous forms of relief. For SOTER delineation map hypsometric analysis is based on DEM interval classification [9].

The elevations interval of Lebanon begins from 0 the coastal plain increasing in altitude to $3080 \mathrm{~m}$ the highest mountain of Kornet Es Sawda.

Table 1

Shows the classes of the Lebanese terrain

\begin{tabular}{|c|c|}
\hline Hypsometry class & Elevation interval (meters above the sea Level) \\
\hline 1 & $0-10$ \\
\hline 2 & $10-50$ \\
\hline 3 & $50-100$ \\
\hline 4 & $100-200$ \\
\hline 5 & $200-300$ \\
\hline 6 & $300-600$ \\
\hline 7 & $600-1500$ \\
\hline 8 & $1500-3000$ \\
\hline
\end{tabular}

Slope.Slope is one of the most fundamental measures of landscape characteristics and first vertical derivative of elevation [12]. Slope refers to the angle of inclination of a land surface above the horizontal.

Slope can be calculated by geographic information systems through many mathematical formulas $[6,36$, $22,33,34,38]$. The accuracy of each method of slope calculation varies, and is dependent on the quality and spatial precision of the base DEM.

The most common method for calculating slope in a geographic information system raster is to compute the 'spatial derivative' [4,5]. The derivative expresses the rate of change of the data.The first derivative of elevation is the slope and is calculated as follows:

$$
\text { Slope } \%=100 * \sqrt{\left(\frac{\Delta Z x}{\Delta X}\right)^{2}+\left(\frac{\Delta Z y}{\Delta Y}\right)^{2}}
$$

Where: $\Delta \mathrm{Zx}=$ change in elevation in the $\mathrm{x}$ direction

$\Delta \mathrm{Zy}=$ change in elevation in the $\mathrm{y}$ direction

$\Delta \mathrm{X}=$ resolution in the $\mathrm{X}$ direction $(2 *$ grid cell $)$

$\Delta \mathrm{Y}=$ resolution in the $\mathrm{Y}$ direction $(2 *$ grid cell $)$

In raster GISs slope is calculated by passing a $3 \times 3$ kernel over the grid surface; slope for the center cell $\mathrm{E}$ is computed from the surrounding eight cells labeled A, B, C, D, F, G, H and I as follows:

\begin{tabular}{|c|c|c|}
\hline A & B & C \\
\hline D & E & F \\
\hline J & H & I \\
\hline
\end{tabular}

Many algorithms exist to compute slope.Differences between approaches are based on methods used to obtain the $\Delta \mathrm{Z}$ value for center cell $\mathrm{E}$ from cells $\mathrm{A}, \mathrm{B}, \mathrm{C}, \mathrm{D}, \mathrm{F}, \mathrm{G}, \mathrm{H}$ and I.

Slope is one of the most fundamental measures of landscape characteristics and reported as a driving variable in many ecological studies. It has been found to be related to: soil surface depth, subsoil texture, and internal soil drainage, profil, and erosion of soil [34, 43, 50, 49, 41-46].

Slope are calculated with the ArcMap algorithm listed above basing to SRTM data set and classified as suggested by the SOTER Procedure Modification workshop following table 2 classes [9].

Table 2

SOTER classifications as per [9]

\begin{tabular}{|l|c|c|}
\hline & Slope class & Range of slope percentage \\
\hline Flat & 1 & $0-2$ \\
\hline Gently undulating & 2 & $2-5$ \\
\hline Undulating & 3 & $5-10$ \\
\hline Rolling & 4 & $10-15$ \\
\hline Moderately steep & 5 & $15-30$ \\
\hline Steep & 6 & $30-45$ \\
\hline Extreme & 7 & Above 45 \\
\hline
\end{tabular}


The use of reclassified slope according to the SOTER classes in Table 2, gives too much spatial details by defining polygons borders between classes.

Stream density (SD).Stream density $(S D)$ is the total length of the permanent and seasonal streams and rivers divided by a unit size of area $(A)$ :

$$
S D=\frac{\Sigma_{1}^{n} L}{A}
$$

Where $L$ is the length and ' $n$ ' is the number of (streams) rivers [26].

As a parameter in catchment studies stream density can be used in three main ways:

Firstly, it is related to watershed or physiographic characteristics such as relief ratio, rock type and basin shape.

Secondly, it is related to input and output of the drainage basin system.

Thirdly, Stream density may be useful in relation to studies of past [39] and future [42] conditions.

Stream density provides hydro-geomorphologists with a useful measure of landscape dissection and runoff potential. A low value of drainage density indicates a highly permeable landscape, with small potential for runoff. A high value of drainage density indicates a highly dissected surface [25].

Drainage density is clearly an important geomorphic variable [21] that has been related to climatic conditions [7], flood peaks [21], mean annual discharge, and sediment yields.

When calculating stream network lengths using topographic maps, spiridonov recommend dividing maps into a grid of 4 square centimeters [40].

According to the adopted methodology of calculating stream density, we divided the Lebanese territory into equal squares of $2 \times 2$ kilometers within we determined the overall length of the stream network. 2757 squares of 2 kilometers constitute the shape of Lebanon and characteristic the level of details in drawing isodense (isolines of the same drainage density values).

It has to be clarified here that the term 'stream density' is not identical to the one used by geographers and geomorphologists.It is not based on the real stream network; it is only derived from a DEM.Therefore it does not take into consideration the loss of surface water due to infiltration into the soil.

In our study, the stream density map of Lebanon was classified in two classes, the less dissected areas convex surfaces and the more dissected areas concave surfaces table 3 .

Less dissected area have an SD values between 0 and $90 \mathrm{~km} / \mathrm{km}^{2}$ and the more dissected areas above $90 \mathrm{~km} / \mathrm{km}^{2}$

\begin{tabular}{|l|c|}
\hline \multicolumn{1}{|c|}{ Class } & PDD value range $\left(\mathrm{km} / \mathrm{km}^{2}\right)$ \\
\hline $1:$ less dissected areas & $0-90$ \\
\hline 2: more dissected areas & Above 90 \\
\hline
\end{tabular}

Relief Intensity (RI). The degree of dissection is difficult to quantify with the uses of paper maps and traditional methods (ISRIC, 1993). With the appearance of Digital elevation models and GIS technologies it makes feasible to derive an artificial stream network, which characterizes the landscape dissection [10].

The data was processed in three steps. In the first step, a flow direction map was derived for DEM, then a flow-accumulation values and stream network extraction.

The Relief Intensity (RI) is one of the most significant discriminating terrain factors in the SOTER Procedure. It is defined as the difference between the highest and lowest elevations occurring within that area. It is important to note that relief intensity in a lot of articles is termed as "relative relief" In our study we divided the Lebanese shape into a grid of 2 by 2 kilometers with a calculation of all elevations statistics values (minimum, mean and maximum) inside each square of the grid then with the application of the radial basis function we provide an interpolation to build the relief intensity map. The SOTER Procedure Modification workshop came up with a simplified classification (Table 4) [9].

The Relief Intensity classification as suggested by the SOTER Procedure Modification workshop.

Table 4

\begin{tabular}{|c|c|}
\hline Relief Intensity class & Altitude range in meters \\
\hline 1 & $0-50$ \\
\hline 2 & $50-100$ \\
\hline 3 & $100-300$ \\
\hline 4 & Above 300 \\
\hline
\end{tabular}

SOTER Terrain Unit delineation. The SOTER methodology was initially developed as a land resources information system for the scale of 1:1 million [47]. SOTER combines a geometric database with an attribute database, storing the SOTER unit's location. In our recent study we are solving the extraction of the Lebanese territory geometric database which can be used in the future to build a Lithological SOTER map with the combination of a soil attribute data. The SOTER concept is based on the relationship between the physiography (landform), parent materials and soils within a certain area. It identifies landforms with distinctive pattern. 
It is known by many researches that SOTER Unit delineation is based on two primary soil formation phenomena: terrain and lithology. Physiography is the first differentiating criterion to be used to characterize a SOTER Unit. The term physiography is used in this context as the description of the landforms on the Earth's surface. It can be best described as identifying and quantifying the major landforms, on the basis of the dominant gradient of their slopes and their relief intensity. The use of these variables, in combination with hypsometric and stream density, can delineate the study area in units forming the physiography SOTER map.

Worstell B., Edwin Hammond and Dobos, Montanarella have proposed an approach using DEM for SOTER Terrain Unit delineation based on landform classification methods. They used the $1 \mathrm{~km}$ resolution SRTM30 data as the base DEM, which is ten times bigger than SRTM 3 spatial resolution used by us which prove our microscale resolution.

The aim was to apply a quantitative method to derive terrain classes corresponding to the SOTER concept [28] using Shuttle Radar Topography Mission (SRTM) data.

The GIS layers of these attributes were derived from the SRTM digital elevation model by translating and reformatting the terrain class characteristics given by the SOTER manual.

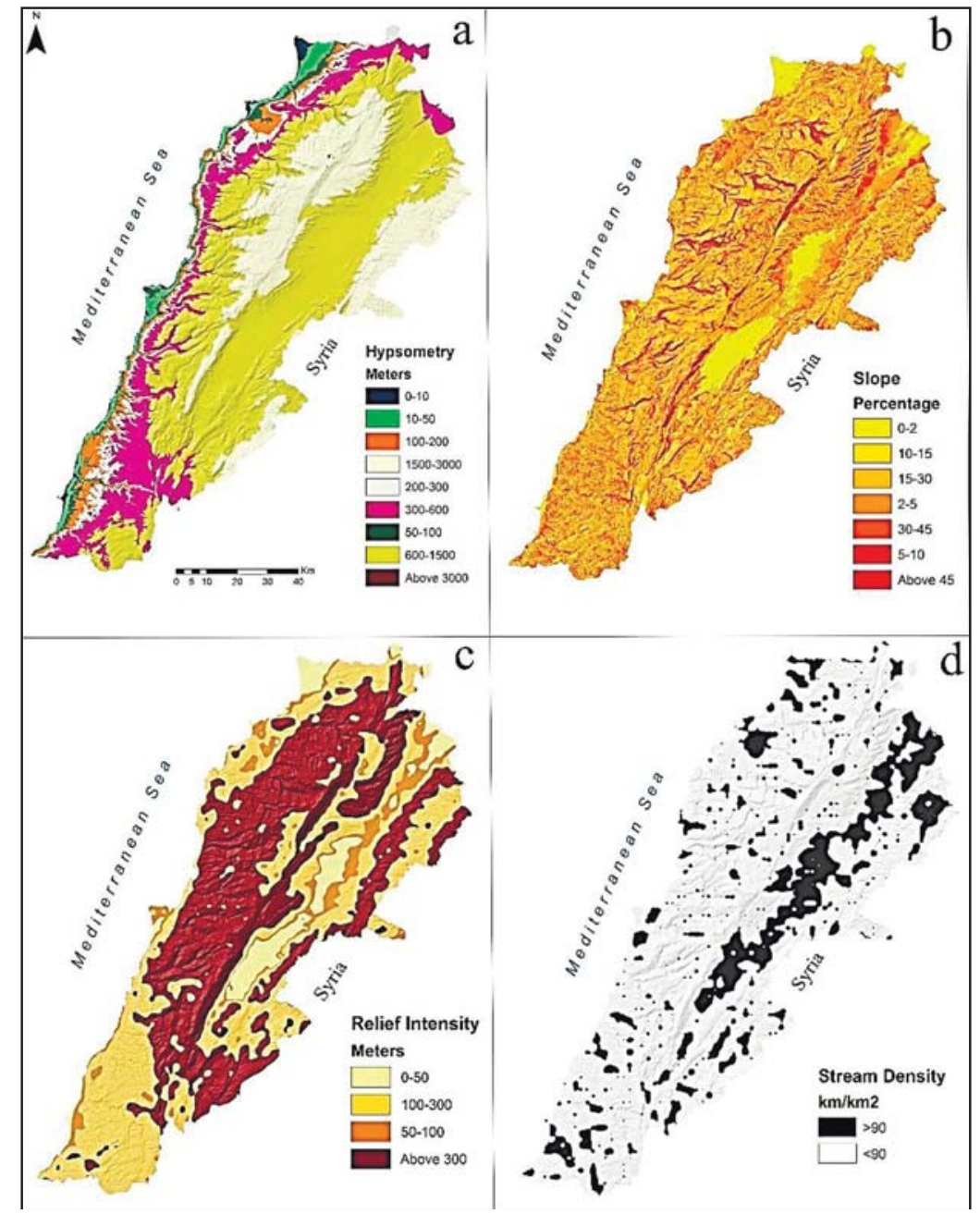

Fig. 1: The four maps of Lebanon derived from SRTM a) hypsometry, b) Slope, c)Relief Intensity, d)Stream Density

As per figure 1 a) the hypsometry map of Lebanon dividing the terrain in 9 intervals of elevations shows a big territory of the study area are within the interval of 600-1500 in dark yellow color including Bekaa valley. Figure $1 \mathrm{c}$ ) the slope map highlight horizontal terrain of non-slope $0-2 \%$ of Bekaa, Akar and coastal plains. The relief intensity map shows a very high amplitude in the mountainous terrain of about 300 meters in dark brown enclosing the Western Lebanese mountain chain. Contrary a very high stream density values in non-mountainous area such as Bekaa, Akar, Koura, Beirut, Damour.

The classifications for the four terrain layers are described in the flowchart used to achieve the work figure 2.

After the extraction and classification of the hypsometry, slope, relief intensity and stream density. The next step in the delineation process was to combine the information from the four SRTM-derived terrain thematic layers as an output we got a raster derived layer of the SOTER unit, this grid had many small patterns.

DEM resolution tends to generalize the land surface and eliminate the Nano-scale patterns of the surface. Thus, a generalization procedure was used to obtain the appropriate raster grid. 


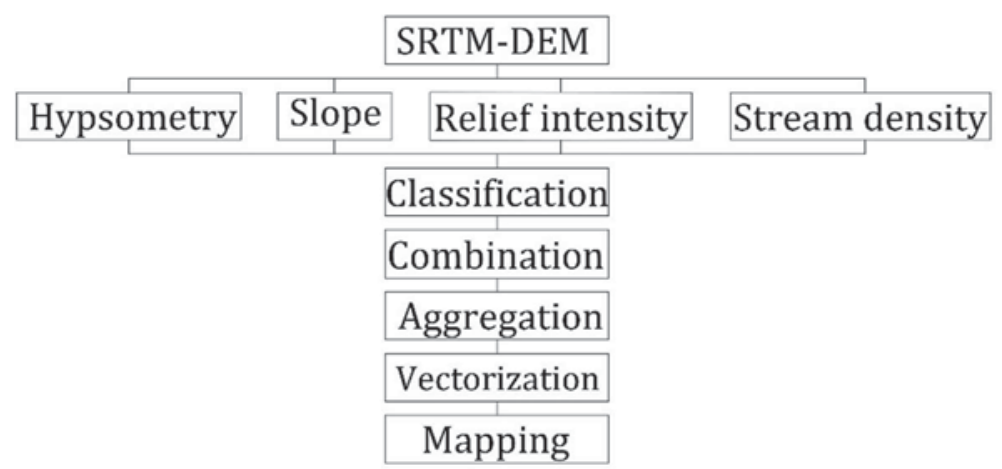

Fig. 2: A flowchart of SOTER terrain unit's delineation

A GIS very useful command of generalization small areas 'aggregate'. Aggregating several small polygons together may result in a new polygon. The procedure is repeated until the resulting polygon system remains stable and all the small polygons disappear. This grid is then vectorized to create a polygon shape file. In the GIS file all common boundaries between the land units of a similar land system have been dissolved, creating a larger mapping unit.

Result and discussion. Four terrain parameters were derived from the SRTM digital elevation model figure 2, after combination of these layers as result of the SOTER terrain unit's delineation, we built the physiography map of Lebanon figure 3.

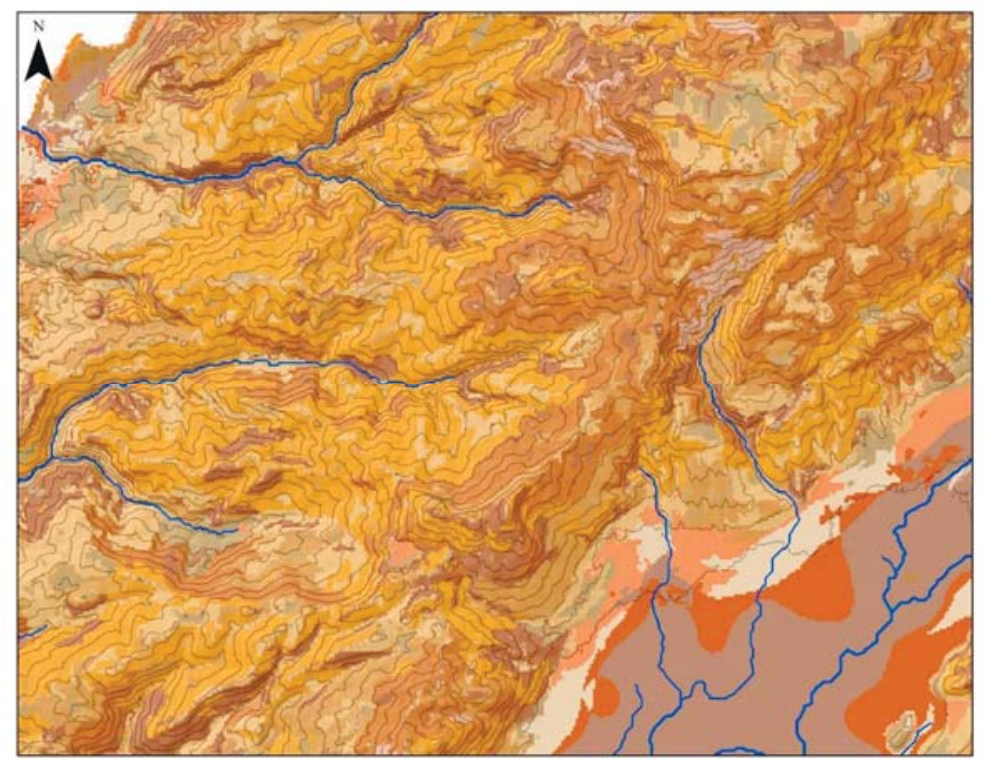

Fig 3: A part of the SOTER Terrain Units polygon map

In figure 3 at the left side on mountainous terrain we can see a diversity of soil units at the lower right area specifically in Bekaa valley only two types of soil terrain units are detected in dark and clear brown.

The polygon system derived by the procedure follows the main geomorphological trends, and identifies terrain units according to the DEM spatial resolution. As a result of the rigorous, quantitative procedure, the polygons represent relatively homogeneous units as far as the four terrain parameters are considered. The quantitative SOTER is fully SRTM based which mean it has the same resolution of 90 meters.

The SOTER physiography map of Lebanon is constitute from 18 units of different terrain structures. The dominated unit's type is the concave foot slope one occupying $17 \%$ from the whole Lebanese territory.

Other wise $0.2 \%$ for the horizontal type of plan areas found in Beirut and Akkar.

If we compare the resulted SOTER physiography map with the UNEP created one we found that it is constitute from 12 units which is very normal in cartographic generalization from a scale to other especially when the spatial resolution is ten times higher.

Based on this experience, we may conclude, that the digital procedure failed to reproduce the same database with different spatial resolution.

Conclusion. Many studies carried out the usefulness of digital elevation models for soil survey and characterization. The Shuttle Radar Topography Mission (SRTM) project developed a global digital elevation model (DEM), which is freely available. These sets of data and technologies can help creating a common platform for the SOTER database development at local scale (country scale). 
We took the opportunity to apply the methodology of SOTER Terrain Unit delineation based on a DEM at a country scale of Lebanon and compare it in the context of the SOTER global project.

This paper describes this new, quantitativemethod for creating a SOTER Terrain Unit polygon system, the resulting SOTER database will have the advantages of quantitatively derived databases, namely consistency, homogeneity, limited data generalization problems, and will avoid edge-matching and harmonization problems. The results are satisfying. The delineation of the terrain features is appropriate to the targeted scales. Meaningful and homogeneous geomorphologic units were identified, hypsometry, relief intensity, slope and stream density. For generalization of the polygon map a computer based GIS tool was applied.

For the first time a geographic information system (GIS) manages the geometric delineation of SOTER units of Lebanon at a local scale (country scale) based on SRTM data sets. The physiography SOTER map of Lebanon could be in a continuous part of a future study a classification of the SOTER Unit according to the lithology needs to be done to complete the delineation procedure for studies of carbon stocks and changes, soil parameter estimation and assessment of land degradation.

\section{REFERENCES}

1. Batjes N.H., A taxotransfer rule-based approach for filling gaps in measured soil data in primary SOTER databases, version 1.0. Technical report 03, ISRIC World Soil Information, Wageningen. - 2003.

2. Batjes N.H., SOTER summary file for Central and Eastern Europe (SOVEUR Project), version1.0. ISRIC Report 06, ISRIC, Wageningen. - 2000.

3. Baumgardner M.F., World Soils and Terrain Digital Database at a scale of 1:1M (SOTER). ISSS, Wageningen Carson B, Shah PB and Maharjan PB 1986.// Land Systems Report, the soil landscapes of Nepal, HMG of Nepal Land Resource Mapping Project carried out by Kenting Earth Sciences Limited, Kathmandu, Nepal. - 1986.

4. Burrough P., McDonnell R. Principles of Geographic Information Systems. Oxford University Press, New York, NY, - 1998, -333 p.

5. Carter J. The Effect of Data Precision on the Calculation of Slope And Aspect Using Gridded DEMs. //Cartographica, - Vol. 29, - №. 1, - 1992, - pp. 22-34.

6. Chang K., Tsai B. The effect of DEM resolution on slope and aspect mapping.//Cartography and GIS, №18(1), - 1991, - pp. 69-77.

7. Chorley R.J., Morgan M. A., Comparison of morphometric features, Unaka Mountains, Tennessee and North Carolina, and Dartmoor,England:Geol.Soc.Am.Bull., - v.73, - 1962, - pp.17-34.

8. Dijkshoorn J.A., van Engelen V.WP and Huting JRM. Soil and landform properties for LADA partner countries (Argentina, China, Cuba, Senegal and Gambia, South Africa and Tunisia), ISRIC- World Soil Information, Wageningen. - 2008 .

9. Dobos E., Daroussin J., Montanarella L. A quantitative procedure for building physiographic units for the European SOTER database. In 'Digital Terrain Modelling.// Development and Applications in a Policy Support Environment, European Commission, Springer. - 2007, - pp.227-259.

10.Dobos E., Micheli E., Baumgardner M.F., Biehl L., Helt T. Use of combined digital elevation model and satellite radiometric data for regional soil mapping. //Geoderma. 97, - 2000, - pp.367-391.

11. Dobos E., Montanarella $L$. The development of a quantitative procedure for soilscape delineation using digital elevation data for Europe. //Digital Soil Mapping workshop, Montpellier, France, - 2004, - pp. 14-17.

12. Evans I. S. General geomorphometry, derivatives of altitude, and descriptive statistics // Spatial Analysis in Geomorphology. L., - 1972.

13. Falorni G., Teles V., Vivoni E.R., Bras R.L., Amaratunga K., Analysis and characterization of the vertical accuracy of digital elevation models from the shuttle radar topography mission. //Journal of Geophysical Research, 110, F02005. - 2005.

14. FAO and UNEP //Land Degradation Assessments for Drylands, FAO 2007.

15. FAO, AGL Global Soil and Terrain Database (WORLD-SOTER), The Food and Agricultural Organization of the United Nations (http://www.fao.org/ag/agl/agll/soter.stm)

16. FAO, ISRIC and National Institutes. //Soil and Terrain database for Central and Eastern Europe, version 1.0, FAO Rome 2000.

17. FAO, ISRIC and UNEP //Soil and Terrain Database for Southern Africa, version1.0, FAO Rome 2003.

18. FAO, ISRIC and Universiteit Gent. //Soil and Terrain Database for Central Africa, Democratic Republic of the Congo, FAO Rome 2007.

19. FAO, ISRIC, UNEP and CIP. //Soil and Terrain database for Latin America and the Caribbean, CDROM, FAO Rome 1998.

20. Gamba P., DellAcqua F., Houshmand B., SRTM data characterization in urban areas.//International Society for Photogrammetry and Remote Sensing Commission III,Symposium 2002.

21. Gardinier V., Gregory K.J. Drainage density in rainfall-runoff modelling in Rainfall-runoff relationship, //Water Resources Publications. V.P. Singh (ed), 449 76.Littleton, colo, - 1982.

22. Green P.J., and Sibson R. 1978. Computing dirichlet tesselation in the plane. //The Computer Journal 21, - pp.168-173. 
23. Guth P., 2003. Geomorphology of DEMs: Quality assessment and scale effects. //Proceedings of GSA, Seattle Annual Meeting, pp. 175-2, - 2003.

24. Hammond E. H., Small scale continental landform maps. //Annals of Association of American Geographers, $-44,-1954,-$ pp. 33-42.

25. Horton R.E. Drainage basin characteristics // Transaction of American Geological Union, - 13, - 1932, - pp. $350-351$.

26. Horton R.E. Erosional development of streams and their drainage basin. // hydrophysical approach to quantitative morphology. Geol. Soc. Amer. Bull., - 56, - 1945, - pp. 275-370.

27. ISRIC, FAO and Ghent University.// Soil and Terrain database for Central Africa, FAO Land and Water Digital Media Series 33. FAO, Rome 2006.

28. ISRIC, Global and National Soils and Terrain Databases (SOTER): //Procedures Manual. UNEP-ISSSISRIC-FAO, Int. Soil Reference and Information Centre, Wageningen, the Netherlands, 1993.

29. ISRIC. SOTER database for LADA partners countries, 2009. (http://www.isric.org/UK/About+Soils/Soil+data/Geographic+data/National/default.htm)

30. ISSS, ISRIC and FAO.// World Reference Base for Soil Resources, Food and Agriculture Organization of the United Nations, Rome Nelson D, Laban P, Shrestha BD and Kandel GP 1980. A Reconnaissance Inventory of the Major Ecological Land Units and their Watershed Conditions in Nepal- Summary Report. FO: DP/NEP/74/020, FAO, HMG of Nepal and UNEP Rome 1998.

31. ISSS. //Proceedings of an International Workshop on the Structure of a Digital International Soil Resources Map annex Database. In: Baumgardner M and L Oldeman, (editors), International Workshop on the Structure of a Digital International Soil Resources Map annex Database. SOTER Report 1. ISSS, Wageningen. - 1986, - 138 p.

32. Kellndorfer J.,WalkerW., Pierce L., Dobson C., Fites J. A., Hunsaker C., et al., Vegetation height estimation from shuttle radar topography mission and national elevation datasets. //Remote sensing of Environment, 93, - 2004, - pp.339-358.

33. McCullagh M. J., Ross C. J. Delaunay trianglulation of a random data set for isarithmic mapping.//The Cartographic Journal 17, - 1980, - pp. 93-99.

34. McKenna D. G. The inward spiral method: an improved TIN generation technique and data structure for land planning applications. //Proc. Auto-Carto 8, - 1987, - pp. 670-679.

35. Pearson R. N. Physical geography. Barnes and Noble, New York, NY, - 1968, - 242p.

36. Peucker T. K., Douglas D. H.Detection of surface specific points by local parallel processing of discrete terrain elevation data. //Computer Graphics and Image Processing 4, - 1974, - pp. 375-387.

37. Pogorelov A.V., Doumit J.A., Classification and allocation of the discrete morphological elements of the digital elevation model //Actual problems of ecology and conservation of ecosystems of southern regions of Russia and adjacent areas: Proceedings of the twentieth inter-republic scientific-practical conference. - Krasnodar: Kuban State University, - 2008, - p.107-109.

38. Scarlatos L.L. An automated critical line detector for digital elevation matrices. //Proc. Auto-Carto 9, 1989, - pp. 146-155.

39. Schumm S. Evolution of drainage systems and slopes in badland at Perth Amboy, New Jersey.//Bulletin of Geological Society of America,67, - 1956, - pp 597-646.

40. Spiridonov A.I. Geomorphological cartography. M. Nedra, $-1975,-184$ p.

41. Stock J. D., Bellugi D., Dietrich W. E., Allen D., Comparison of SRTM topography to USGS and high resolution laser altimetry topography in steep landscapes: Case studies from Oregon and California. //Eos Trans. AGU, Fall Meet. Suppl., Abstract H21G-09, -№ 83, - 2002, - p.47

42. Strahler A.N. Quantitative geomorphology of drainage basins and channel networks.// In Handbook of Applied Hydrology, edited by V.T. Chow, 4-39/4-76. McGraw-Hill, New York, - 1964.

43. Swanston D.N., Dyrness C.T. Stability of steep land. //J. Forest. - 71, - 1973, - pp.264-269.

44. Turner L.M. Factors influencing the rate of growth of pine in Arkansas.// Ecology 17, - 1936. - pp. $227-240$.

45. Turner L.M. Growth of second-growth pine on the coastal plain soils of Arkansas. Arkansas Agr. Exp. Sta., Bull. 342. Fayetteville, AK, $-1937,-52$ p.

46. Turner L.M. Some profile characteristics of the pine-growing soils of the coastal plain region of Arkansas. Arkansas Agr. Exp. Sta., Bull. 361. Fayetteville, AK, - 1938, - 52p.

47. Van Engelen VWP and Wen TT// Global and National Soil and Terrain Digital Database (SOTER). Procedures Manual. ISRIC - World Soil Information, Wageningen. - 1995.

48. Van Engelen VWP, Wen TT. Global and National Soil and Terrain Digital Database (SOTER). Procedures Manual. ISRIC - World Soil Information, Wageningen. - 1995.

49. Verstappen H.T. Applied geomorphology. Elsevier Science Publishing Co. New York, NY, 1983, - 437 p.

50. Way D.S. Terrain analysis: a guide to site selection using aerial photographic interpretation. Dowden, Hutchinson, and Ross Inc., Stroudsburg, PA, - 1973, - 392 p.

51. Worstell B. Development of soil terrain (SOTER) map units using digital elevation models (DEM) and ancillary digital data. M.Sc. Thesis. Purdue University, Indiana, USA. - 2000. 